\title{
Mastl overexpression is associated with epithelial to mesenchymal transition and predicts a poor clinical outcome in gastric cancer
}

\author{
XIAN-JUN SUN ${ }^{1,2}$, YAN-LIANG LI ${ }^{1}$, LONG-GANG WANG ${ }^{1}$, \\ LI-QING LIU ${ }^{1}$, HENG MA ${ }^{1}$, WEN-HONG HOU ${ }^{3}$ and JIN-MING YU ${ }^{2,3}$ \\ ${ }^{1}$ Department of Gastrointestinal Surgery, Shandong Cancer Hospital and Institute, Jinan, Shandong 250117; \\ ${ }^{2}$ Department of Oncology, Tianjin Medical University, Tianjin 300070; ${ }^{3}$ Department of Radiotherapy, \\ Shandong Cancer Hospital and Institute, Jinan, Shandong 250117, P.R. China
}

Received January 14, 2016; Accepted July 3, 2017

DOI: $10.3892 / \mathrm{ol} .2017 .7155$

\begin{abstract}
Microtubule-associated serine/threonine kinase like (Mastl) is deregulated in a number of types of human malignancy and may be a kinase target for cancer treatment. The aim of the present study was to determine the Mastl expression in gastric cancer and to clarify its clinical and prognostic significance. Immunohistochemistry was performed on a cohort of 126 postoperative gastric cancer samples to detect the expression of Mastl and two epithelial to mesenchymal transition (EMT) markers, epithelial-cadherin and Vimentin. The $\chi^{2}$ test, Kaplan-Meier estimator analysis and Cox's regression model were used to analyze the data. Upregulated Mastl protein expression was observed in the gastric cancer tissues compared with that in the adjacent non-cancerous gastric tissues. Increased Mastl expression was identified in 54/126 (42.9\%) gastric cancer samples, and was significantly associated with lymph node metastasis, tumor relapse, EMT status and poor overall survival. Additional analysis demonstrated that the Mastl expression level stratified the patient outcome in stage III, but not stage II tumor subgroups. Cox's regression analysis revealed that increased Mastl expression was an independent prognostic factor for patients with gastric cancer. Mastl expression may be a valuable prognostic marker and a potential target for patients with gastric cancer.
\end{abstract}

\section{Introduction}

Gastric carcinoma remains one of the most common and lethal types of malignancy worldwide (1). Although patients receive radical surgery and chemotherapy, recurrence and metastasis remain a challenge for this type of malignancy (2). Therefore,

Correspondence to: Dr Jin-Ming Yu, Department of Oncology, Tianjin Medical University, 22 Qixiangtai Road, Tianjin 300070, P.R. China

E-mail: sdyujinming@126.com

Key words: microtubule-associated serine/threonine kinase like, epithelial to mesenchymal transition, kinase, prognosis, target the identification of novel therapeutic targets and prognostic factors for patients with gastric cancer is required.

Kinases represent a group of promising therapeutic targets for cancers. Identification of novel specific kinase targets and prognostic factors may not only expand upon the options of treatments for patients with gastric cancer, but also provide classifiers to discriminate subgroups that may benefit from kinase inhibitors (3).

The microtubule-associated serine/threonine kinase like (Mastl) gene encodes a kinase that promotes mitotic progression and cell cycle re-entry following DNA damage $(4,5)$. A previous study demonstrated that Mastl was commonly overexpressed in a number of types of cancer, including breast and oral cancer (6). Furthermore, Mastl upregulation was associated with recurrence following initial cancer therapy and decreased patient survival in a number of cancer types $(6,7)$. These previous studies indicated that Mastl may be a novel therapeutic target for cancer. In spite of this, the expression of Mastl in patients with gastric cancer has not been investigated and limited information is known about the mechanisms of Mastl with respect to tumor progression. In the present study, it was hypothesized that Mastl may induce epithelial to mesenchymal transition (EMT) and consequently promote tumor migration and metastasis. Therefore, the present study aimed to investigate the expression level of Mastl and EMT-associated proteins in a cohort of patients with gastric cancer, and to evaluate the associated clinical significance and correlation.

\section{Materials and methods}

Patients and tissue specimens. The present study was approved by the Ethics Committee of Shandong Cancer Hospital and Institute (Jinan, China). A cohort of 152 tumor node metastasis (TNM) (8) stage II/III patients with gastric cancer (84 male, 68 female; median age 52 years, range 28-75 years), who underwent gastrectomy with lymph node dissection between July 2006 and December 2010, were included in this retrospective study. TNM staging, histology and margins were classified or defined according to the Chinese guidelines for diagnosis and treatment of gastric cancer (2011 edition) (8). The following exclusion criteria were predefined: i) Patients with $\mathrm{R} 1 / \mathrm{R} 2$ margins (as defined by the aforementioned guidelines); 
ii) patients who succumbed during the peri-operative period; and iii) patients receiving preoperative chemotherapy or radiotherapy. Finally, a total of 126 patients with advanced disease (where metastasis or recurrence occurred during the follow-up period) received postoperative platinum-based chemotherapy with or without radiotherapy were included in the present study following the exclusion of 26 cases. All patients were followed up subsequent to surgery. Examinations for recurrence or metastasis were performed using serum tumor marker assays, including carcinoembryonic antigen, and diagnostic imaging (computed tomography, ultrasonography or magnetic resonance imaging) every 3 months for the initial 2 postoperative years and subsequently every 6 months. The median follow-up time was 60 months (range, 1-111 months). Patients who experienced distant metastases or recurrence during follow-up received oxaliplatin $\left(85 \mathrm{mg} / \mathrm{m}^{2}\right.$, every 2 weeks), docetaxel $\left(75 \mathrm{mg} / \mathrm{m}^{2}\right.$, every 3 weeks) or irinotecan $\left(150-180 \mathrm{mg} / \mathrm{m}^{2}\right.$, every 2 weeks) single agent chemotherapy, or treatment in combination with cetuximab $\left(500 \mathrm{mg} / \mathrm{m}^{2}\right.$, every 2 weeks $)$ or bevacizumab (5 mg/kg, every 2 weeks) regimens (8).

Immunohistochemistry (IHC). Immunohistochemical staining was performed to determine the protein expression of Mastl, Vimentin and epithelial (E-)cadherin in 126 gastric cancer tissues. Briefly, $4-\mu \mathrm{m} 10 \%$ formalin-fixed (1 day at room temperature) paraffin embedded sections were dewaxed in xylene and antigen was retrieved by heating the sections $\left(95^{\circ} \mathrm{C}\right.$ for $30 \mathrm{~min}$ ) in $10 \mathrm{mmol} / \mathrm{l}$ citrate solution ( $\mathrm{pH} 6.0$ ) for $30 \mathrm{~min}$. After blocking the endogenous peroxidase activity, using $3 \%$ $\mathrm{H}_{2} \mathrm{O}_{2}$ (10 min at room temperature), anti-Mastl (\#15739-1-AP, ProteinTech Group, Inc., Chicago, IL, USA), anti-Vimentin (\#10366-1-AP, ProteinTech Group, Inc.) and anti-E-Cadherin (\#20874-1-AP, ProteinTech Group, Inc.) (all dilution at 1:100) antibodies were incubated with the sections overnight at $4^{\circ} \mathrm{C}$. Subsequently, sections were washed and treated with biotinylated horseradish peroxidase-labeled anti rabbit secondary antibody (\#sc-2357, Santa Cruz Biotechnology, Inc., Dallas, TX, USA, 1:100) at $37^{\circ} \mathrm{C}$ for $30 \mathrm{~min}$. Diaminobenzene was used to detect chromogen and hematoxylin was used as the nuclear counterstain at room temperature for $1 \mathrm{~min}$, and staining was observed under light microscope (magnification, $\mathrm{x} 40$ ). Non-specific rabbit immunoglobulin G (\#sc-2027, at 1:100 dilution, Santa Cruz Biotechnology, Inc.) was used to replace the primary antibodies in immunohistostaining as negative controls.

Evaluation of immunohistochemical staining. The immunostaining was scored by two independent senior pathologists who were unaware of the patients' clinical information. For Mastl staining, an immunoreactive score (IRS) was derived by addition of the intensity score $(0$, negative to weak; 1 , positive; and 2, strongly positive) and the density score (0, $0-25 \%$ of tumor area stained; 1, 26-50; 2, 51-75; and 3, 76-100\%) for statistical analysis with respect to each patient. An IRS score of $\geq 4$ was defined as high expression and $<4$ was defined as low expression, as described previously (9). The membranous E-cadherin and cytoplasmic vimentin expression was defined according to previously published guidelines (10). The slides were graded as follows: Grade 1, 0-25\% staining; grade 2, $26-50 \%$ staining; and grade $3,>50 \%$ staining. According to
Table I. Association between Mastl expression and clinicopathological features.

\begin{tabular}{|c|c|c|c|}
\hline \multirow[b]{2}{*}{ Prognostic factor } & \multicolumn{2}{|c|}{ Mastl expression } & \multirow[b]{2}{*}{ P-value } \\
\hline & Low & High & \\
\hline Age, years & & & 0.634 \\
\hline$<60$ & 20 & 18 & \\
\hline$\geq 60$ & 52 & 36 & \\
\hline Sex & & & 0.938 \\
\hline Male & 42 & 31 & \\
\hline Female & 30 & 23 & \\
\hline Pathology type & & & 0.362 \\
\hline Differentiated & 52 & 34 & \\
\hline Undifferentiated & 20 & 20 & \\
\hline Tumor size $^{\mathrm{a}}$ & & & 0.501 \\
\hline $\mathrm{T} 2-3$ & 51 & 42 & \\
\hline $\mathrm{T} 4$ & 21 & 12 & \\
\hline Lymph node ${ }^{a}$ & & & 0.013 \\
\hline N0 & 42 & 21 & \\
\hline N1 & 27 & 23 & \\
\hline $\mathrm{N} 2$ & 3 & 10 & \\
\hline Recurrence & & & 0.016 \\
\hline Negative & 58 & 32 & \\
\hline Positive & 14 & 22 & \\
\hline EMT status & & & 0.029 \\
\hline Wild-type & 60 & 35 & \\
\hline Undergoing EMT & 12 & 19 & \\
\hline
\end{tabular}

${ }^{a}$ Tumor node metastasis staging system. Mastl, microtubule-associated serine/threonine kinase like; EMT, epithelial to mesenchymal transition.

previous criteria (11), patients with vimentin or E-cadherin expression of greater than or equal to grade 1 were classified as exhibiting positive EMT status, while the other patients were defined as the wild-type group.

Statistical analysis. The $\chi^{2}$ test or Fisher's exact test was used to evaluate the association between Mastl expression, the clinicopathological variables and EMT status. Kaplan-Meier estimator curves were plotted using a log-rank test for univariable analysis of overall survival and differences between the groups were evaluated using the log-rank test. Multivariable Cox's proportional hazards regression models were used to assess the prognostic significance of Mastl expression and of several accepted prognostic factors. Statistical analysis was performed using the GraphPad Prism 5.0 software package (GraphPad Software, Inc., San Diego, USA). P $<0.05$ was considered to indicate a statistically significant difference.

\section{Results}

Table I lists the clinicopathological characteristics of the 126 patients with gastric cancer patients included in the present 
A

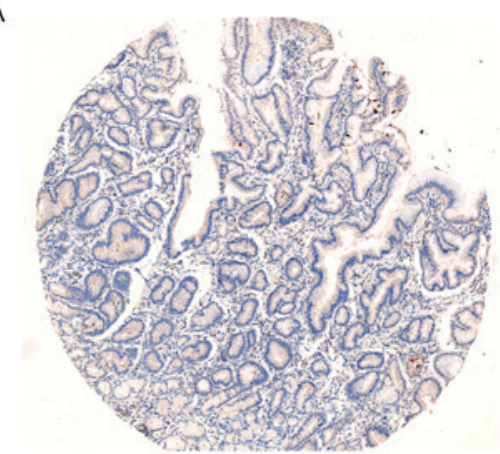

D

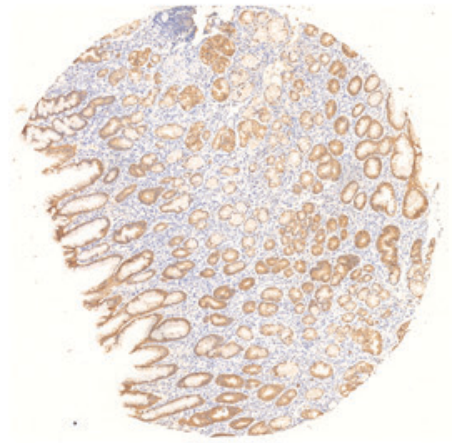

G

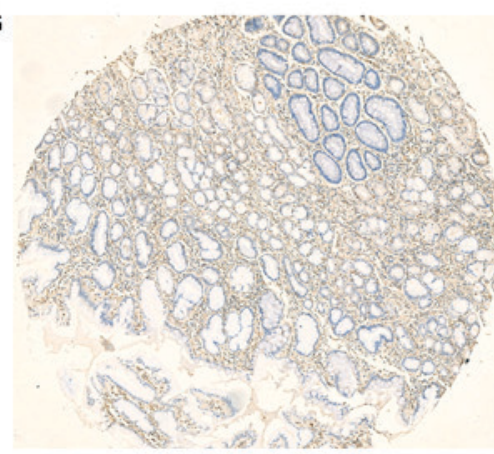

B

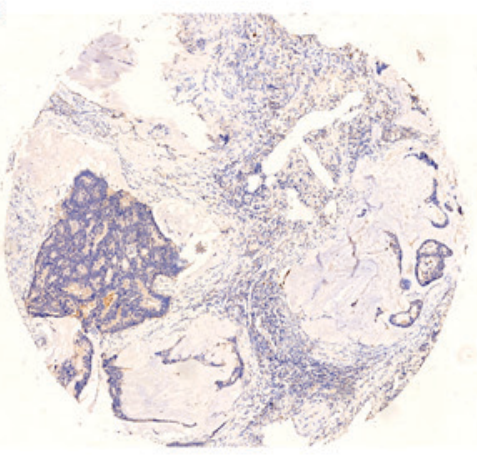

E

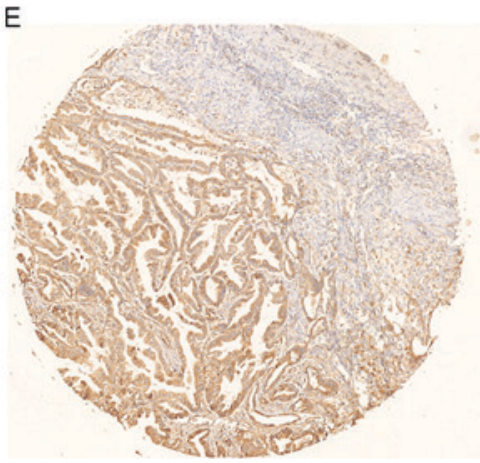

$\mathrm{H}$

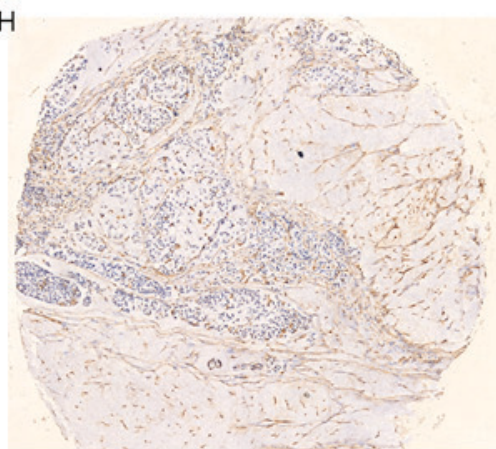

C

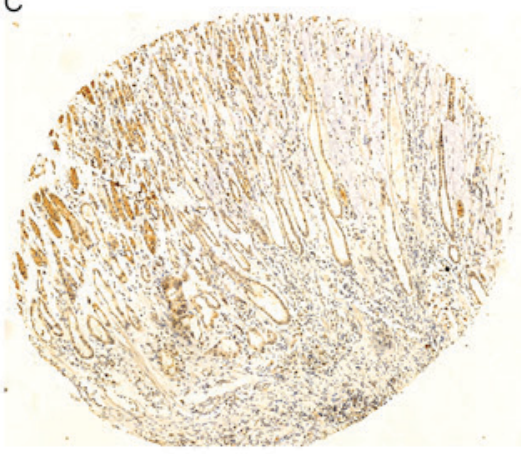

F

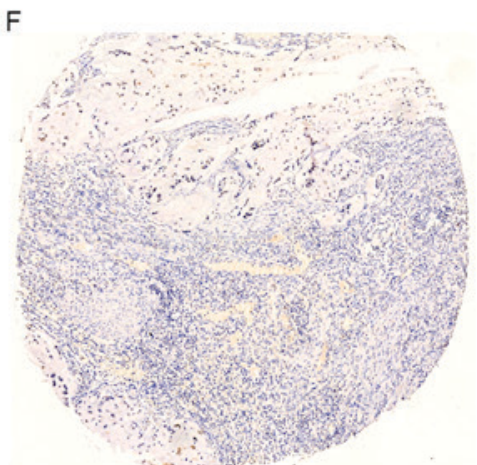

I

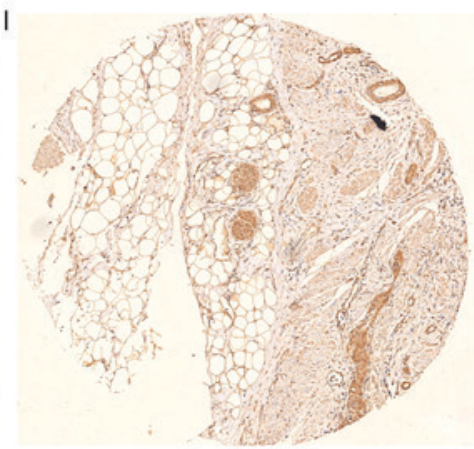

Figure 1. Representative images of immunostaining of Mastl, E-Cadherin and Vimentin. (A) Negative Mastl staining in normal gastric epithelium. (B) Gastric carcinomas with weak Mastl staining. (C) Strong Mastl staining intensity in primary gastric cancer tissues. Strong E-cadherin staining in (D) normal gastric epithelium and (E) gastric cancer tissues. (F) Weak staining of E-cadherin in gastric cancer tissues. Negative vimentin staining in (G) normal and (H) cancerous epithelium, but positive staining in the stroma. (I) Positive vimentin staining in the malignant epithelium of gastric cancer tissues. Mastl, microtubule-associated serine/threonine kinase like; E-cadherin, epithelial cadherin (magnification, $\mathrm{x} 4$ ).

study. First, the Mastl expression level in gastric cancer and adjacent normal gastric tissues was analyzed using IHC. The representative images of immunohistochemical staining are presented in Fig. 1. Mastl immunoreactivity was primarily within the membranes and cytoplasm of the gastric cancer cells. The majority of the stroma or normal gastric cells exhibited negative staining, in spite of sporadic positive staining on these cells. According to the IHC analysis, the patients were separated into two groups: High Mastl expression (IRS $\geq 4$ ) and low Mastl expression (IRS<4). Furthermore, 54/126 (42.9\%) cases exhibited high expression of Mastl in the gastric cancer tissues.

The association between Mastl protein expression and the clinicopathological characteristics of gastric cancer was subsequently determined. This analysis revealed that increased expression of Mastl was positively associated with lymph node metastasis $(\mathrm{P}=0.013)$ and tumor recurrence $(\mathrm{P}=0.016)$. However, no association between Mastl expression and other clinicopathological features was observed (Table I).
As seen in Fig. 1, Positive E-cadherin staining was observed in normal and part of the malignant gastric epithelium, and vimentin staining was observed in all the stroma and part of the cancerous epithelium. On the basis of the IHC results of Vimentin and E-cadherin and the aforementioned previously published criteria (11), the patients were separated into two groups: EMT type and wild-type. A total of 31/126 $(24.6 \%)$ cases were defined as the EMT type in the gastric cancer cohort. Increased Mastl expression was identified to be significantly associated with EMT status $(\mathrm{P}=0.029)$.

The patients with high Mastl expression exhibited a significantly decreased overall survival (OS) time compared with that of the patients with low Mastl expression [hazard ratio (HR), 2.591; 95\% confidence interval (CI), 1.535-4.374; log-rank test, $\mathrm{P}<0.001$ ] (Fig. 2; Table II). Furthermore, a survival analysis was performed according to the level of Mastl expression in subsets of patients with gastric cancer at different clinical stages. The results demonstrated that high 
Table II. Prognostic factors on univariable and multivariable Cox proportional hazards regression models for overall survival in stage II and III colorectal cancer patients.

\begin{tabular}{|c|c|c|c|c|c|c|}
\hline \multirow[b]{2}{*}{ Prognostic factor } & \multicolumn{3}{|c|}{ Univariable } & \multicolumn{3}{|c|}{ Multivariable } \\
\hline & HR & $95 \% \mathrm{CI}$ & P-value & HR & $95 \% \mathrm{CI}$ & P-value \\
\hline Age, years & & & & & & \\
\hline$<60$ vs. $\geq 60$ & 1.557 & $0.908-2.671$ & 0.141 & & & \\
\hline Sex & & & & & & \\
\hline Male vs. female & 0.756 & $0.455-1.249$ & 0.281 & & & \\
\hline Pathology type & & & & & & \\
\hline Undifferentiated vs. differentiated & 1.638 & $0.930-2.882$ & 0.058 & & & \\
\hline $\begin{array}{l}\text { Tumor size } \\
\text { T4 vs. T2-3 }\end{array}$ & 1.299 & $0.724-2.332$ & 0.347 & & & \\
\hline $\begin{array}{l}\text { Lymph node } \\
\text { Positive vs. negative }\end{array}$ & 1.826 & $1.104-3.022$ & 0.019 & 1.681 & $1.130-2.501$ & 0.011 \\
\hline $\begin{array}{l}\text { Mastl expression } \\
\text { High vs. low }\end{array}$ & 2.591 & $1.535-4.374$ & $<0.001$ & 2.006 & $1.176-3.420$ & 0.010 \\
\hline $\begin{array}{l}\text { EMT status } \\
\text { Undergoing EMT vs. wild-type }\end{array}$ & 2.893 & $1.490-5.617$ & $<0.001$ & 2.605 & $1.533-4.426$ & $<0.001$ \\
\hline
\end{tabular}

Mastl, microtubule-associated serine/threonine kinase like; EMT, epithelial to mesenchymal transition; HR, hazard ratio; CI, confidence interval.

A

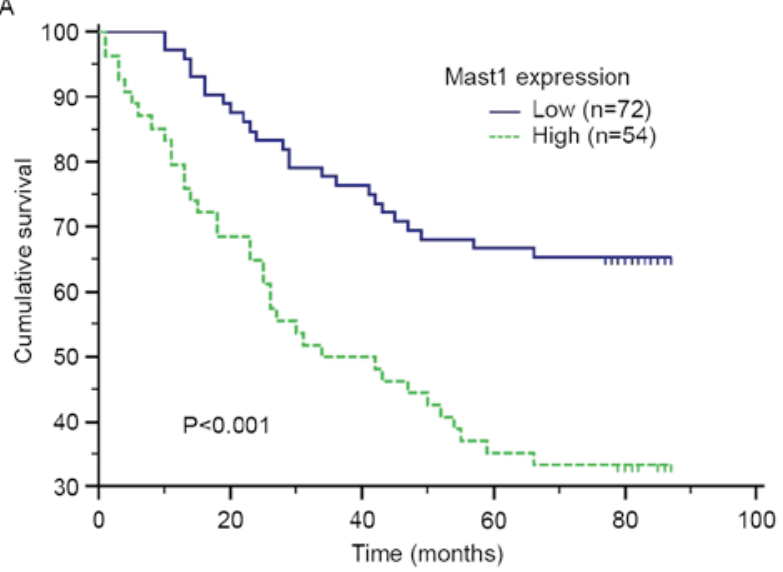

C

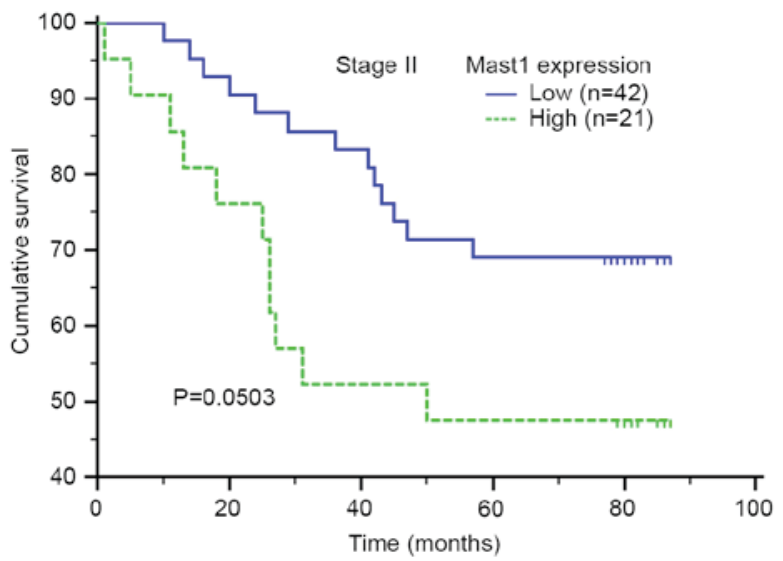

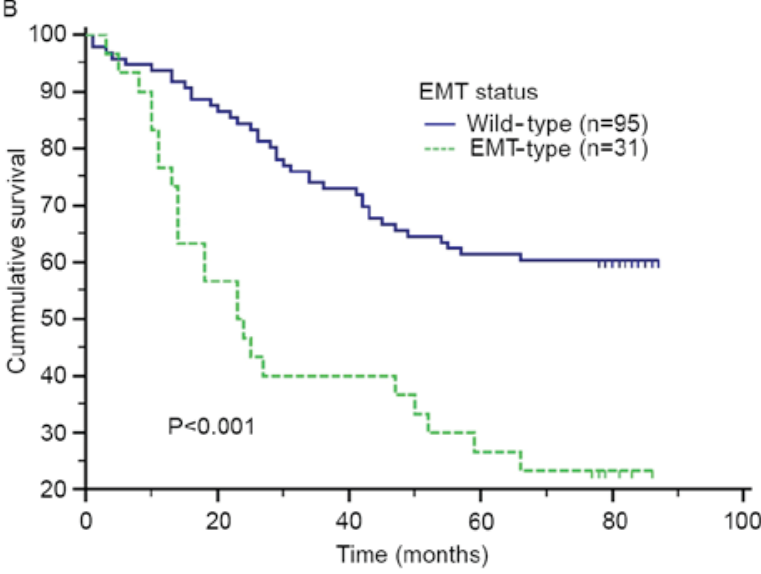

D

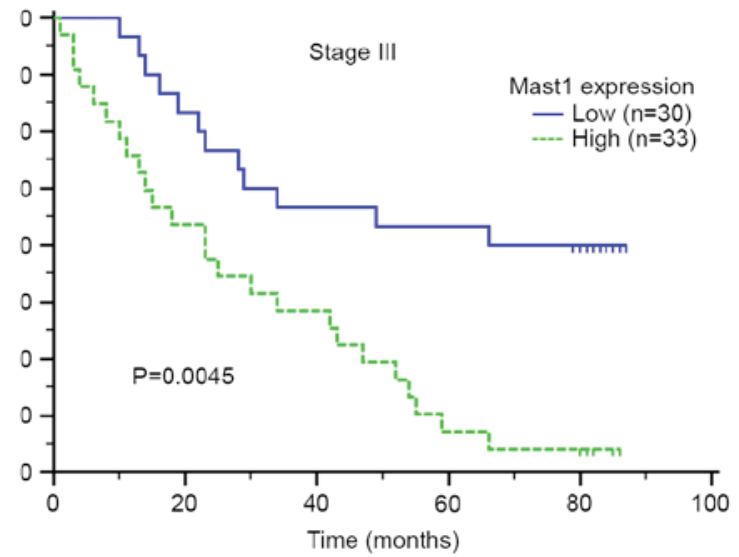

Figure 2. Prognostic value of Mastl expression and EMT status in gastric cancer. (A) Probability of OS for all GC patients with low and high Mastl expression. (B) Probability of OS for all GC patients undergoing EMT and with wild-type status. (C) Probability of OS for stage II GC patients with low and high Mastl expression. (D) Probability of OS for stage III GC patients with low and high Mastl expression. Mastl, microtubule-associated serine/threonine kinase like; EMT, epithelial to mesenchymal transition; OS, overall survival; GC, gastric cancer. 
expression of Mastl was a prognostic factor for the patients with stage III disease (HR, 2.590; 95\% CI, 1.355-4.953; log-rank test, $\mathrm{P}=0.0045$ ) (Fig. 2). However, Mastl expression levels failed to retain prognostic significance for the patients at stage II (HR, 2.1810; 95\% CI, 0.8943-5.3190; log-rank test, $\mathrm{P}=0.0503$ ) (Fig. 2).

Clinical characteristics were included in the univariate analysis to assess their impact on the survival of patients with gastric cancer; positive lymph node metastasis, underlying EMT status and high Mastl expression were identified to be prognostic factors, but were not associated with each other. On multivariable analysis adjusted for established clinical prognostic factors, high Mastl expression was a prognostic factor of OS time (HR, 2.006; 95\% CI, 1.176-3.420; $\mathrm{P}=0.010$ ), as was the presence of lymph node metastasis (HR, 1.681; 95\% CI, 1.130-2.501; $\mathrm{P}=0.011)$ and EMT status (HR, 2.605; 95\% CI, 1.533-4.426; $\mathrm{P}<0.001)$.

\section{Discussion}

The clinical significance of Mastl expression has been investigated only in oral and breast cancer (6). To the best of our knowledge, the present study was the first to clinically evaluate the expression of Mastl and its significance in gastric cancer. The results of the present study identified that Mastl protein was upregulated in the gastric cancer tissues, relative to the normal adjacent non-cancerous tissues, which was consistent with the results of a previous study of oral cancer tissues and healthy controls (6). Furthermore, analysis of gastric cancer tissues revealed a significant association between Mastl expression with aggressive characteristics and poor patient survival, which is consistent with the results of a previous study of breast cancer (7). Therefore, the present study revealed Mastl as a candidate oncogene and a potential prognostic factor in cancer, and Mastl-positive gastric cancer may require intensive treatments.

Mastl-knockdown in recurrent tumor cells may re-sensitize their response to chemotherapy and radiotherapy in vitro and in vivo, indicating that Mastl is a novel therapeutic target for tumor recurrence (6). In vitro studies have indicated a number of possible mechanisms for this effect, including Mastl acting as a cyclin-dependent kinase dephosphorylation inhibitor and a regulator of the DNA damage response $(12,5)$. However, the association between Mastl and tumor recurrence remains unknown. In the present study, it was validated that, in gastric cancer samples, Mastl was associated with EMT status. Previous studies have identified that EMT is involved in tumor recurrence and the resistance to initial cancer therapy $(13,14)$, and the results of the present study support this.

Polo-like kinase 1 (Plk1), aurora kinases and Mastl represent a group of promising serine/threonine kinase targets for cancer treatment. Inhibitors of Plk1 and aurora kinases are currently under clinical development for cancer therapy $(15,16)$. On the basis of the biological and the clinical significance of Mastl in the present and previous studies, it has been hypothesized that Mastl may sensitize the response to initial cancer therapy in gastric cancer, thus decreasing the incidence of tumor recurrence. Additionally, potential Mast1 inhibitors deserve future investigation.
To the best of our knowledge, the results of the present study were the first to indicate that Mastl expression is associated with EMT status, tumor recurrence and poor survival in gastric cancer. The expression of Mastl, as determined using IHC, may serve as an independent predictor of clinical outcome for patients with gastric cancer. The results of the present study suggested that Mastl may serve as a promising therapeutic target for gastric cancer. Additional studies are required to investigate the clinical potential of Mastl inhibition for gastric cancer therapy.

\section{References}

1. Siegel RL, Miller KD and Jemal A: Cancer statistics, 2016. CA Cancer J Clin 66: 7-30, 2016.

2. Yang L: Incidence and mortality of gastric cancer in China. World J Gastroenterol 12: 17-20, 2006.

3. Fleuren ED, Zhang L, Wu J and Daly RJ: The kinome 'at large' in cancer. Nat Rev Cancer 16: 83-98, 2016.

4. Álvarez-Fernández M, Sánchez-Martínez R, Sanz-Castillo B, Gan PP, Sanz-Flores M, Trakala M, Ruiz-Torres M, Lorca T, Castro A and Malumbres M: Greatwall is essential to prevent mitotic collapse after nuclear envelope breakdown in mammals. Proc Natl Acad Sci USA 110: 17374-17379, 2013

5. Peng A, Yamamoto TM, Goldberg ML and Maller JL: A novel role for greatwall kinase in recovery from DNA damage. Cell Cycle 9: 4364-4369, 2010.

6. Wang L, Luong VQ, Giannini PJ and Peng A: Mastl kinase, a promising therapeutic target, promotes cancer recurrence. Oncotarget 5: 11479-11489, 2014.

7. Dahlhaus M, Burkovski A, Hertwig F, Mussel C, Volland R, Fischer M, Debatin KM, Kestler HA and Beltinger C: Boolean modeling identifies Greatwall/MASTL as an important regulator in the AURKA network of neuroblastoma. Cancer Lett 371: 79-89, 2016.

8. Ji J: Chinese guidelines for diagnosis and treatment of gastric cancer (2011 edition). Transl Gastrointest Cancer 1: 103-114, 2012.

9. Remmele W and Stegner HE: Recommendation for uniform definition of an immunoreactive score (IRS) for immunohistochemical estrogen receptor detection (ER-ICA) in breast cancer tissue. Pathologe 8: 138-140, 1987 (In German).

10. Yamada S, Fuchs BC, Fujii T, Shimoyama Y, Sugimoto H, Nomoto S, Takeda S, Tanabe KK, Kodera Y and Nakao A: Epithelial-to-mesenchymal transition predicts prognosis of pancreatic cancer. Surgery 154: 946-954, 2013.

11. Yang MH, Hsu DS, Wang HW, Wang HJ, Lan HY, Yang WH, Huang CH, Kao SY, Tzeng CH, Tai SK, et al: Bmil is essential in Twist1-induced epithelial-mesenchymal transition. Nat Cell Biol 12: 982-992, 2010.

12. Manchado E, Guillamot M, de Cárcer G, Eguren M, Trickey M, García-Higuera I, Moreno S, Yamano H, Cañamero M and Malumbres M: Targeting mitotic exit leads to tumor regression in vivo: Modulation by Cdk1, Mastl, and the PP2A/B55a, $\delta$ phosphatase. Cancer Cell 18: 641-654, 2010.

13. Smith BN and Bhowmick NA: Role of EMT in metastasis and therapy resistance. J Clin Med 5: pii: E17, 2016.

14. Mitra A, Mishra L and Li S: EMT, CTCs and CSCs in tumor relapse and drug-resistance. Oncotarget 6: 10697-10711, 2015.

15. Frost A, Mross K, Steinbild S, Hedbom S, Unger C, Kaiser R, Trommeshauser D and Munzert G: Phase i study of the Plk1 inhibitor BI 2536 administered intravenously on three consecutive days in advanced solid tumours. Curr Oncol 19: e28-e35, 2012.

16. Traynor AM, Hewitt M, Liu G, Flaherty KT, Clark J,Freedman SJ, Scott BB, Leighton AM, Watson PA, Zhao B, et al: Phase I dose escalation study of MK-0457, a novel Aurora kinase inhibitor, in adult patients with advanced solid tumors. Cancer Chemother Pharmacol 67: 305-314, 2011. 